\title{
Oxidation of beryllium and exposure of beryllium oxide to deuterium plasmas in PISCES B
}

\author{
J. Roth ${ }^{\mathrm{a}}$, R. Doerner ${ }^{\mathrm{b}}$, M. Baldwin ${ }^{\mathrm{b}}$, T. Dittmar ${ }^{\mathrm{b}}, \mathrm{H} . \mathrm{Xu}^{\mathrm{c}}$, K. Sugiyama ${ }^{\mathrm{a}}$, M. Reinelt ${ }^{\mathrm{a}}$, Ch. \\ Linsmeier ${ }^{\mathrm{a}}$, M. Oberkofler ${ }^{\mathrm{a}, *}$ \\ ${ }^{a}$ Max Planck Institute for Plasma Physics, EURATOM Association, Boltzmannstr. 2, 85748 Garching, \\ Germany \\ ${ }^{b}$ Center for Energy Research, University of California-San Diego, 9500 Gilman Dr., San Diego, CA \\ 92093-0417, USA \\ ${ }^{c}$ General Atomic, CA 92121-1194 San Diego, USA
}

\begin{abstract}
:
The oxidation behaviour of Be in air was studied as a function of temperature. Below $660^{\circ} \mathrm{C}$ oxidation is limited by diffusion of Be through the growing $\mathrm{BeO}$ layer and closed oxide layers up to $100 \mathrm{~nm}$ thickness are formed. Above $660^{\circ} \mathrm{C}$ a rapid increase in the oxidation rate sets in. Secondary electron micrographs show that this fast oxidation goes along with massive structural changes of the surfaces.

Oxidized samples were exposed on the witness-manipulator of PISCES-B to deuterium atoms reflected from a plasma-exposed $\mathrm{W}$ target. The energy of the reflected $\mathrm{D}$ was varied by changing the bias voltage on the $\mathrm{W}$ target (floating, $-50 \mathrm{~V}$ and $-100 \mathrm{~V}$ ). The $\mathrm{BeO}$ temperature during exposure was varied between 20 and $250^{\circ} \mathrm{C}$. The erosion of the exposed surfaces and the uptake of $\mathrm{D}$ were investigated by ion beam analysis. The retained amount of $\mathrm{D}$ increases with increasing bias voltage and decreasing exposure temperature. At room temperature saturation of the D concentration at about 12 at\% in a surface layer correlated to the maximum particle range is observed. At temperatures above $100^{\circ} \mathrm{C}$ the concentration level decreases strongly, but retention spreads over the total oxide thickness.
\end{abstract}

PACS. No. 52.40.Hf (Plasma-wall interactions); 68.47.Gh (Oxide surfaces); 67.63.Gh (Hydrogen and isotopes)

PSI Keywords: First wall, Beryllium, Oxidation, Deuterium inventory,

*Corresponding author:

Martin Oberkofler, Max Planck Institute for Plasma Physics, EURATOM Association, Boltzmannstr. 2, 85748

Garching, Germany, Martin.Oberkofler@ipp.mpg.de

Presenting author:

Joachim Roth, Joachim.Roth@ipp.mpg.de 


\section{Introduction:}

In ITER the first wall in the main plasma chamber will be covered with $\mathrm{Be}\left[{ }^{1}\right]$ in order to avoid risks connected to high central impurity radiation and to profit from the oxygen gettering capability of Be. Although the erosion yield of Be due to light ion bombardment is high, the central impurity radiation remains tolerable. However, the lifetime of Be wall components may reduce the operation time in ITER to less than 5000 discharges and may require improved wall design for more homogeneous loading and/or for easier replacement $\left[{ }^{2}\right]$.

Tritium retention in Be due to implantation is tolerable as the retention saturates within the ion range $\left[{ }^{3},{ }^{4},{ }^{5},{ }^{6}\right]$ without inward diffusion. However, the uptake of hydrogen isotopes in deposited Be layers dominates all other retention processes and limits the operational time when the critical tritium inventory of $700 \mathrm{~g}$ is reached $\left[{ }^{2}\right]$. In co-deposition of hydrogen with Be the influence of oxygen is not resolved indicating that the relation of incident Be, D and O fluxes is of importance $\left[{ }^{7},{ }^{9}, 9\right]$. Another critical issue is the temperature at which Be layers and dust particles are rapidly oxidised in the interaction with steam from a water leak, leading to hydrogen production and explosion hazards.

Therefore, the investigation of Be oxidation and its influence on erosion and hydrogen retention are of vital interest.. Previous oxidation studies $\left[{ }^{10}\right]$ up to $600^{\circ} \mathrm{C}$ have demonstrated that as the oxide layer grows the oxidation rate decreases at constant temperature with the square root of oxide thickness. Oxidation was shown to be controlled by thermal diffusion of Be through the oxide layer and oxidation at the surface. There is a need to extend these investigations to higher temperatures and thicker oxide layers, as earlier results indicate "catastrophic oxidation" $\left[{ }^{11}\right]$. With respect of Be dust formation the deposited and oxidized layer structure is of importance. Hydrogen isotope retention in $\mathrm{BeO}$ was studied in ion beam experiments in the 1970 s up to relatively low fluences of $10^{21} / \mathrm{m}^{2}$ indicating saturation correlated with the ion range as in pure Be $\left[{ }^{12},{ }^{13}\right]$. In this paper Be oxidation studies are extended to $700^{\circ} \mathrm{C}$. Results for $\mathrm{D}$ retention at particle energies between 5 and $100 \mathrm{eV}$ and fluences up to $10^{24} \mathrm{D} / \mathrm{m}^{2}$ are given from experiments in PISCES B.

\section{Experimental:}

Three types of Be samples were used for oxidation studies: machined $25 \mathrm{~mm}$ diameter discs of S-65C Be supplied by Brush Wellman, $4 \mu \mathrm{m}$ Be coatings on polished Al samples, and 10 mm diameter mirror-like polished Be samples from Goodfellow. 
Oxidation was investigated in air in the temperature range between 100 and $700^{\circ} \mathrm{C}$. For the oxidation the chamber for thermal desorption spectroscopy (TDS) within the PISCES B enclosure was used $\left[{ }^{14}\right]$. The quartz-tube in the oven was open to air, the oven temperature set and monitored by a thermal couple. The temperature was ramped up within few minutes to the desired temperature and held for a standard time of 6 hrs. For the rough Be samples and the Be coatings the analysis was done by monitoring the weight increase after oxidation and by AUGER depth profiling using the AES system Phi 590 (Physical Electronics). Sputter profiling was done using a keV Ar beam and the oxide layer was defined from the transition from $\mathrm{BeO}$ to pure $\mathrm{Be}$. The etching depth was calibrated with a standard $100 \mathrm{~nm} \mathrm{SiO}_{2}$ layer. The highly polished samples were used for ion beam depth profiling which yields also details of the composition of the oxide layer. RBS depth profiling was done at the Tandem accelerator at IPP Garching using $800 \mathrm{keV}{ }^{4} \mathrm{He}$ resulting in a depth resolution of $7 \mathrm{~nm}\left[{ }^{15}\right]$. The as-received Be sheet and as-coated Be sample both showed a BeO layer of 4-5 nm while the highly polished and out-gassed Be samples had a surface coverage of $3 \times 10^{16} \mathrm{O}$-atoms $/ \mathrm{cm}^{2}$, equivalent to less than $4 \mathrm{~nm}$ of stoichiometric BeO.

The implantation of the oxidised samples was done in PISCES B. The samples were not in direct plasma contact but mounted on the witness probe manipulator directed under $45^{\circ}$ towards a plasma-exposed $\mathrm{W}$ target and exposed to reflected $\mathrm{D}$ atoms $\left[{ }^{16}\right]$. The samples are shielded against direct ion impact from the plasma while the mean free path of reflected neutrals was long enough to ensure that most reflected neutral particles reached the sample. The solid angle of the holder cap (with a diameter of $38 \mathrm{~mm}$ ) was determined from geometry to $1 / 1061$, the typical exposure time was 4000 s. The D-flux to the $\mathrm{W}$ target was set to $2 \times 10^{22}$ $\mathrm{D} / \mathrm{m}^{2} \mathrm{~s}$ and consists of $34 \% \mathrm{D}^{+}, 44 \% \mathrm{D}_{2}{ }^{+}$and $22 \% \mathrm{D}_{3}{ }^{+}$ions $\left[{ }^{17}\right]$, the reflected particle flux and energy distribution was calculated using SRIM $\left[{ }^{18}\right]$. The reflected particle energy could be varied by changing the bias to the $\mathrm{W}$ target between $-100 \mathrm{~V},-50 \mathrm{~V}$ and floating potential. The range distribution within the BeO layer was calculated using TRIDYN $\left[{ }^{19}\right]$ taking into account sputtering of the layer and associated compositional changes. Fig. 1 shows an example calculation for reflected $\mathrm{D}$ atoms for a bias of $-100 \mathrm{~V}$. The corresponding depth distributions of $\mathrm{Be}, \mathrm{O}$ and $\mathrm{D}$ within the $\mathrm{BeO}$ layer were calculated assuming a saturation concentration within the ion range of 12 at\% taken from literature $\left[{ }^{13},{ }^{20}\right]$.

The $\mathrm{D}$ content in the samples and its depth distribution was analysed by nuclear reaction analysis (NRA) using $800 \mathrm{keV}{ }^{3} \mathrm{He}\left[{ }^{21}\right]$. The total amount was obtained from the produced 
protons while the depth distribution was evaluated using SIMNRA $\left[{ }^{22}\right]$ from the emitted ${ }^{4} \mathrm{He}$ ions at 78 deg to the surface normal. The depth resolution for D near the surface is $\sim 40 \mathrm{~nm}$.

\section{Results:}

Oxidation:

Fig. 2 shows the dependence of the oxide thickness on temperature for a constant oxidation time of 6 hrs. As the exact composition of the oxide layer is not known in all cases, the areal density of incorporated oxygen is plotted to allow the comparison for the different analysis techniques. Different analysis techniques agree within the error introduced by uncertainties, e.g. regarding the atomic density of the oxygen-rich layer. An analytic description of the oxidation process [10] is also shown which results from diffusion of Be through the oxide and oxidation at the surface. The model coincides with the experiments on polished Be at temperatures below $660^{\circ} \mathrm{C}$. The experimental results from the rough discs lie a factor of three above the ones deduced from the model.

At $660^{\circ} \mathrm{C}$ a $100 \mathrm{~nm}$ thick oxide layer develops. Few degrees above this temperature a much more rapid oxidation process starts, increasing eventually the total amount of oxygen by a factor of 100 at $700^{\circ} \mathrm{C}$. At these temperatures the surface topography changes drastically as observed in SEM images (Fig. 3): while up to $660^{\circ} \mathrm{C}$ it reflected still the polished Be substrate, above this temperature the oxide layer ruptures into $\mu \mathrm{m}$-sized clods. It must be assumed that the oxidation is no longer limited by diffusion of Be to the surface through a closed oxide layer but rather occurs directly at the BeO-Be interface with molecular oxygen diffusing through open cracks in the layer. As D depth profiling was not possible on such rough surfaces no further samples were oxidized at $700^{\circ} \mathrm{C}$.

\section{D uptake in Be-oxide:}

The uptake of $\mathrm{D}$ atoms reflected from the plasma bombarded $\mathrm{W}$ target in the BeO layer was measured from the protons emitted in the NRA and is shown in Fig. 4. The total retention at constant fluence increases monotonically with the energy of reflected D atoms. The data points below $200 \mathrm{eV}$ in Fig. 4 were obtained in the present investigation, while the insert shows the agreement with data at higher ion energy $\left[{ }^{13},{ }^{23}\right]$. The blue curve shows the calculated maximum range of the atoms into the oxide in units of $(\mathrm{Be}+\mathrm{O})$ atoms $/ \mathrm{m}^{2}$ multiplied with a $\mathrm{D}$ saturation concentration of 12 at\% within this range as was directly measured after ion implantation at $5 \mathrm{keV}$ [13]. Fig. 5 shows that the total D retention remains constant within the error bars up to temperatures of $100^{\circ} \mathrm{C}$ and decreases by roughly a factor of 2 at $250^{\circ} \mathrm{C}$. 
At the low energies the D concentration reached at saturation at room temperature cannot, however, be determined directly from NRA depth profiling, as the depth resolution is larger than the ion ranges. Fig. 6 shows a sequence of depth profiles of Be, O and D in the sample after loading with $\mathrm{D}$ at a bias of $-100 \mathrm{~V}$. For the case of exposure at room temperature a D profile is shown that corresponds to saturation within the maximum particle range. However, an equally good fit could be obtained for a broader profile within the indicated resolution. At elevated temperatures the depth profile clearly extends to a thickness where it can be resolved. The associated saturation levels decrease to 1 at $\%$ at $100^{\circ} \mathrm{C}$ and below 0.5 at $\%$ at $250^{\circ} \mathrm{C}$. At these temperatures the $\mathrm{D}$ retention becomes uniform throughout the oxide layer. Such a behavior has been postulated already earlier from higher energy implantation data [13].

\section{Erosion:}

Within the sensitivity of RBS used for the oxide layer analysis erosion could only be determined at the highest particle energies, i.e. at a bias voltage of $-100 \mathrm{eV}$ yielding an energy distribution as shown in Fig. 1. At an incident particle fluence of about $5 \times 10^{23} \mathrm{D} / \mathrm{m}^{2}$ a uniform erosion could be seen over the exposed circular spot on the witness probe, amounting to removal of $1.5 \times 10^{21}(\mathrm{Be}+\mathrm{O}) / \mathrm{m}^{2}$. This corresponds to an erosion yield of $3 \times 10^{-3}$. Previous measurements of deuterium sputtering yields of $\mathrm{BeO}$ resulted in values of $5 \times 10^{-3}$ at an incident

$\mathrm{D}$ energy of $60 \mathrm{eV}\left[{ }^{24},{ }^{25}\right]$. This corresponds well to the estimation of 30 to $50 \mathrm{eV}$ for the energy range of the majority of the reflected $\mathrm{D}$ atoms from the $\mathrm{W}$ target (Fig. 1).

Despite this considerable erosion at room temperature the composition of the oxide did not deviate from the stoichiometric BeO composition formed after oxidation (Fig. 6) for any of the applied particle energies. However, at temperatures of $100^{\circ} \mathrm{C}$ and $250^{\circ} \mathrm{C}$, a preferential loss of $\mathrm{O}$ is found near the surface resulting for $100^{\circ} \mathrm{C}$ in a concentration of 43 at\% $\mathrm{O}$ and 57 at\% Be (Fig. 6). This cannot be a physical sputtering effect, as due to kinematic energy transfer rather a preferential erosion of Be would be expected. The reemission of $\mathrm{D}$, assumed to occur in the form of $\mathrm{D}_{2}$ at room temperature, must include $\mathrm{D}_{2} \mathrm{O}$ molecules at elevated temperatures. This process can be interpreted as increased $\mathrm{O}$ erosion by “chemical sputtering” and a yield of the order of $10^{-4}$ can be deduced from the preferential loss of $\mathrm{O}$.

\section{Conclusions:}

On untreated, as received Be surfaces, a thin oxide layer of the order of 4nm prevents further oxidation. The formation of thick oxide layers is limited by thermal diffusion of Be 
atoms to the surface where the arriving Be atoms are oxidised. As the oxide layer grows the oxidation rate decreases at constant temperature with the square root of oxide thickness. An analytic description of this process [10] is confirmed for air exposure up to $660^{\circ} \mathrm{C}$.

At $660^{\circ} \mathrm{C}$ a $100 \mathrm{~nm}$ thick stoichiometric $\mathrm{BeO}$ oxide is formed within 6 hrs exposure to air. At higher temperatures the oxide film breaks into clods and rapid further oxidation becomes possible, most probably at the interface between oxide and Be substrate, no longer limited by diffusion through the layer. This transition determines the critical temperature for rapid oxidation of large dust particles under steam ingress, leading to hydrogen formation, to be about $660^{\circ} \mathrm{C}$, being a safety concern in ITER.

Exposure of the oxide layer to low energy D particle fluxes at room temperature leads to no change of the $\mathrm{BeO}$ stoichiometry, while at $100^{\circ} \mathrm{C}$ and above, a small preferential release of oxygen upon exposure of the $\mathrm{BeO}$ layer to energetic $\mathrm{D}$ atoms is seen. At room temperature the retention of $\mathrm{D}$ in the layer shows a dependence on particle energy indicating a correlation of the retained amount of $\mathrm{D}$ with the maximum particle range. At the low particle energies the maximum particle range can exceed the mean particle range by factors of 3 and more. Using the maximum range, a saturation in lattice concentration of about 12 at $\%$ is deduced. While this saturation concentration could be directly measured only at ion energies in the keV range $[13,23]$ this dependence even holds down to few eV, where the actual depth distribution of $\mathrm{D}$ is much shorter than the resolution of NRA.

At elevated temperatures above $100^{\circ} \mathrm{C}$, the depth distribution broadens and $\mathrm{D}$ is retained at lower saturation concentrations, but throughout the total oxide layer. In this case the retained D will be proportional to the oxide thickness and can even exceed the values at room temperature. 


\section{Figure captions:}

Fig. 1: Calculation of reflected particle energy for the molecular ion mix of PISCES B

Fig. 2: Oxidation of Be samples with different roughness measured by various techniques. For comparison the analytic description from $\left[{ }^{10}\right]$ is shown.

Fig. 3: SEM images of the Be surface after oxidation at $660^{\circ} \mathrm{C}$ and $700^{\circ} \mathrm{C}$

Fig. 4: Energy dependence of retained D areal density in comparison with calculations of the retained $\mathrm{D}$ within the maximum ion range, assuming saturation at $12 \mathrm{at} \%$. Higher energy data, shown in the insert are taken from literature $\left[{ }^{13},{ }^{23},{ }^{26}\right]$.

Fig. 5: Temperature dependence of retained $\mathrm{D}$ at $-100 \mathrm{~V}$ bias as function of temperature

Fig. 6: Depth profiles of composition of Be-oxide layers after implantation at different temperatures 
Fig. 1: Calculation of reflected particle energy for the molecular ion mix of PISCES B

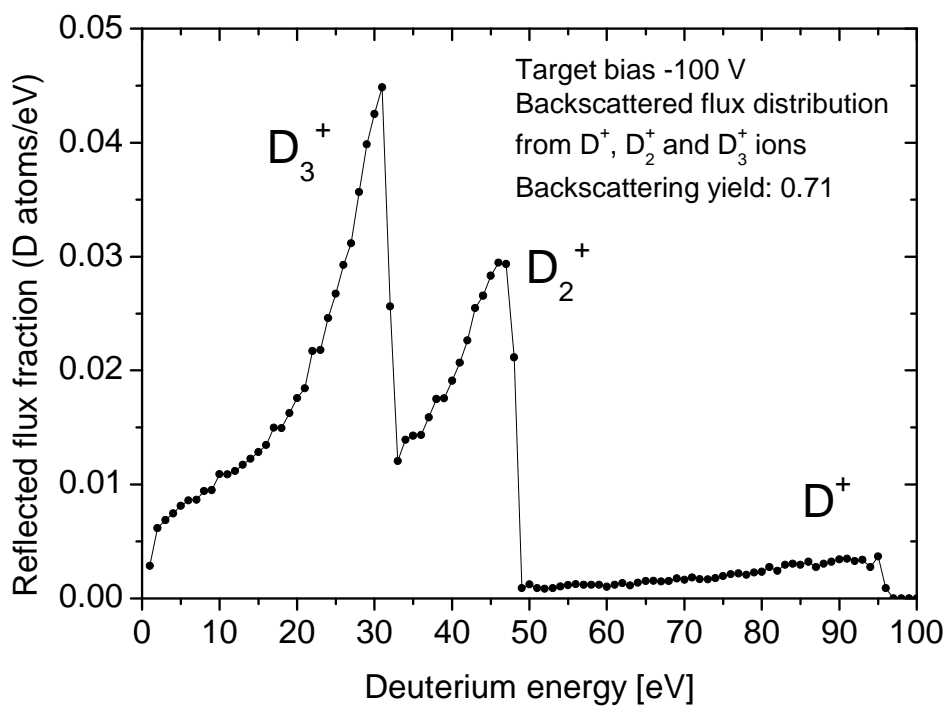


Fig. 2: Oxidation of Be samples with different roughness measured by various techniques. For comparison the analytic description from $\left[{ }^{10}\right]$ is shown.

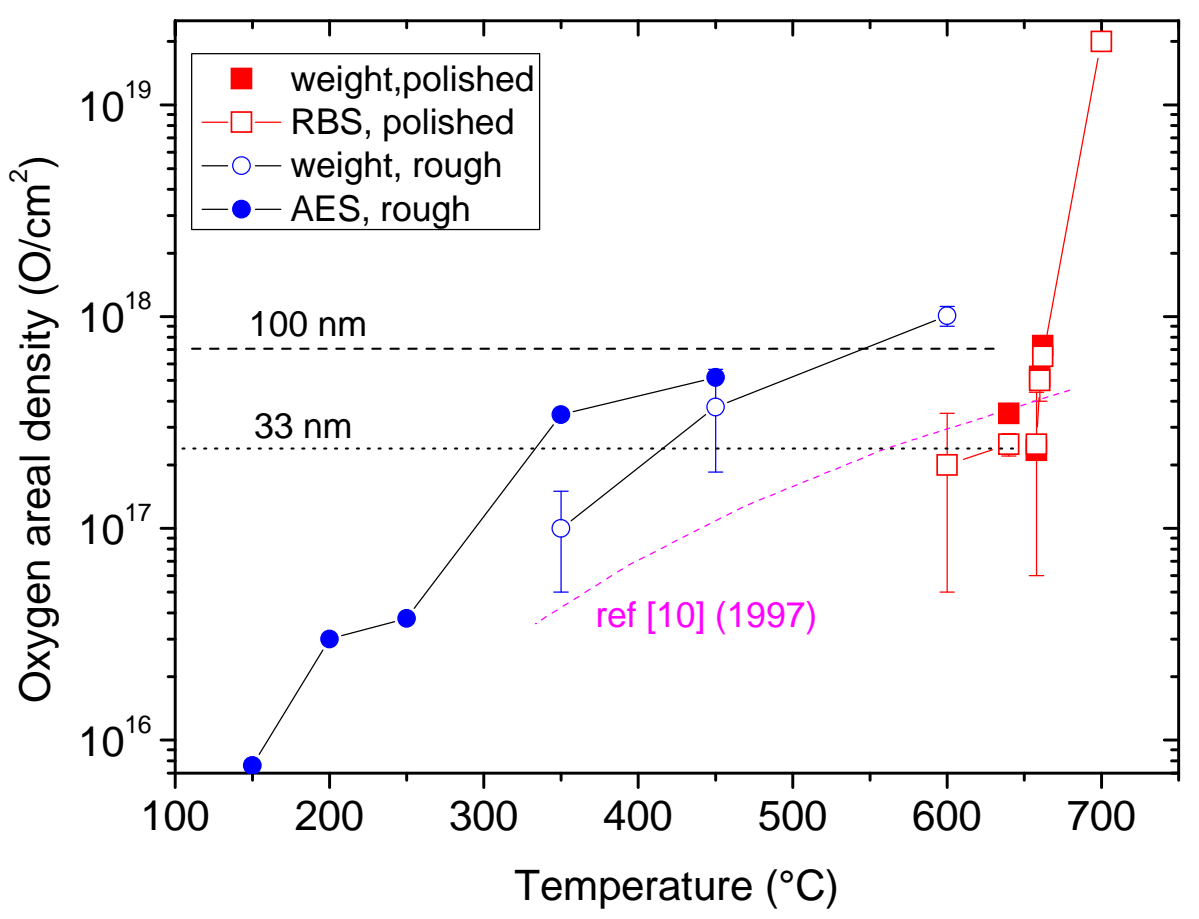


Fig. 3: SEM images of the Be surface after oxidation at $660^{\circ} \mathrm{C}$ and $700^{\circ} \mathrm{C}$
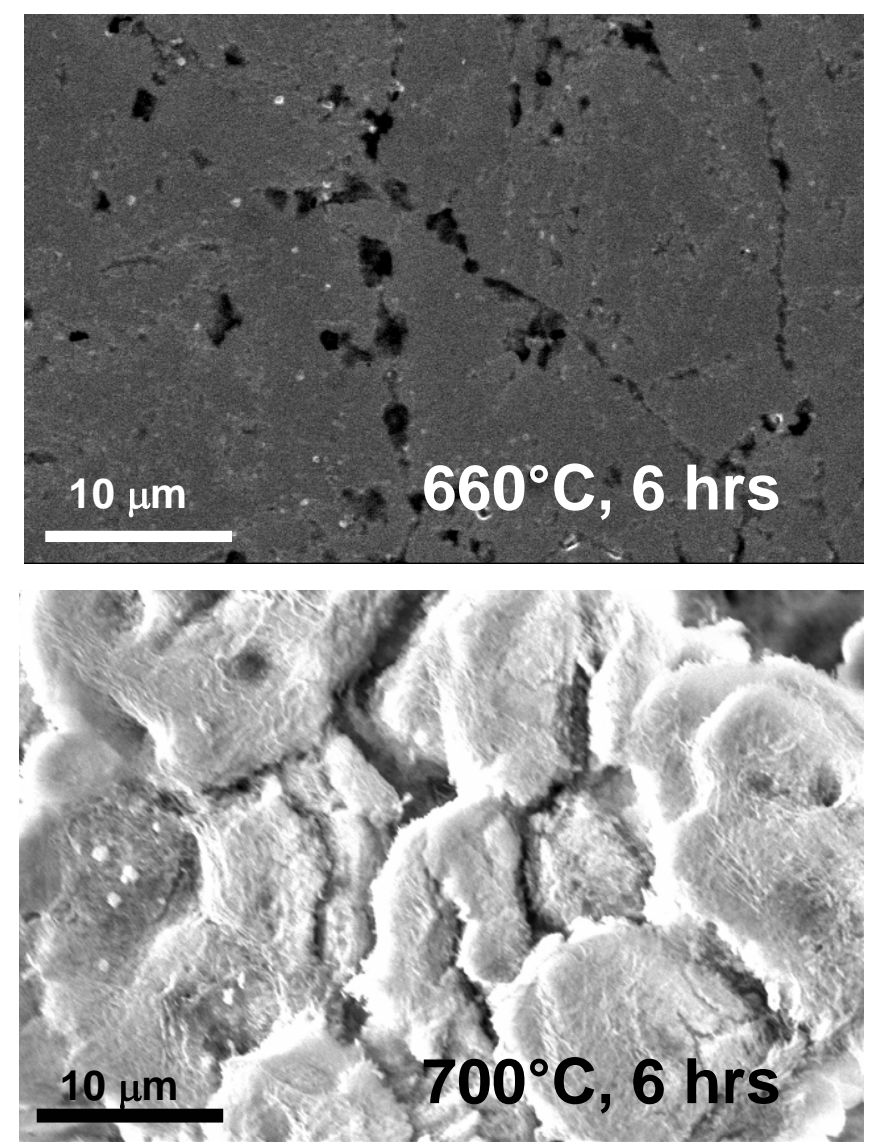
Fig. 4: Energy dependence of retained D areal density in comparison with TRIDYN calculations of the retained D within the maximum ion range, assuming saturation at 12 at\%. Higher energy data, shown in the insert, are taken from literature $\left[{ }^{13},{ }^{23},{ }^{26}\right]$.

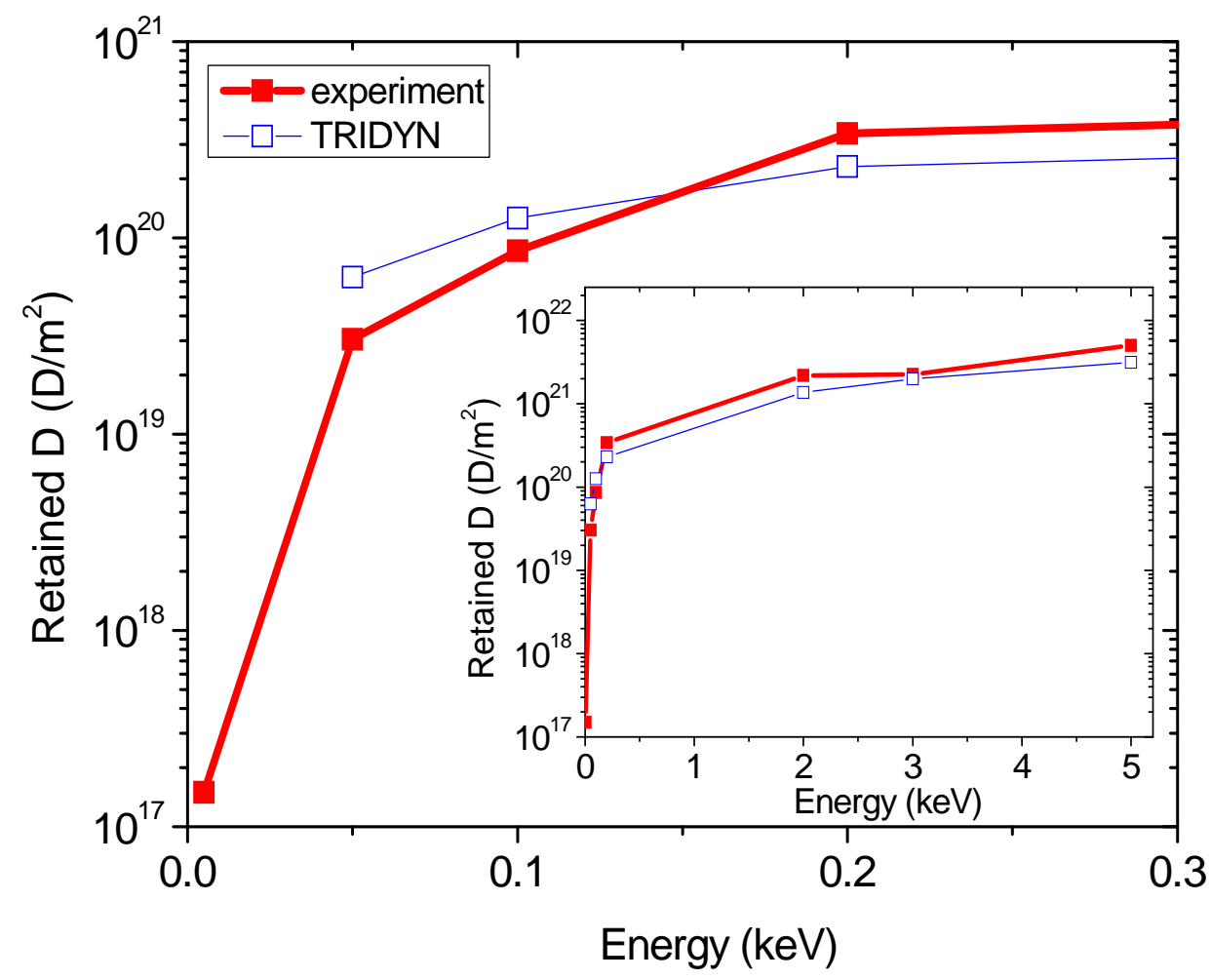


Fig. 5: Temperature dependence of retained $\mathrm{D}$ at $-100 \mathrm{~V}$ bias as function of temperature

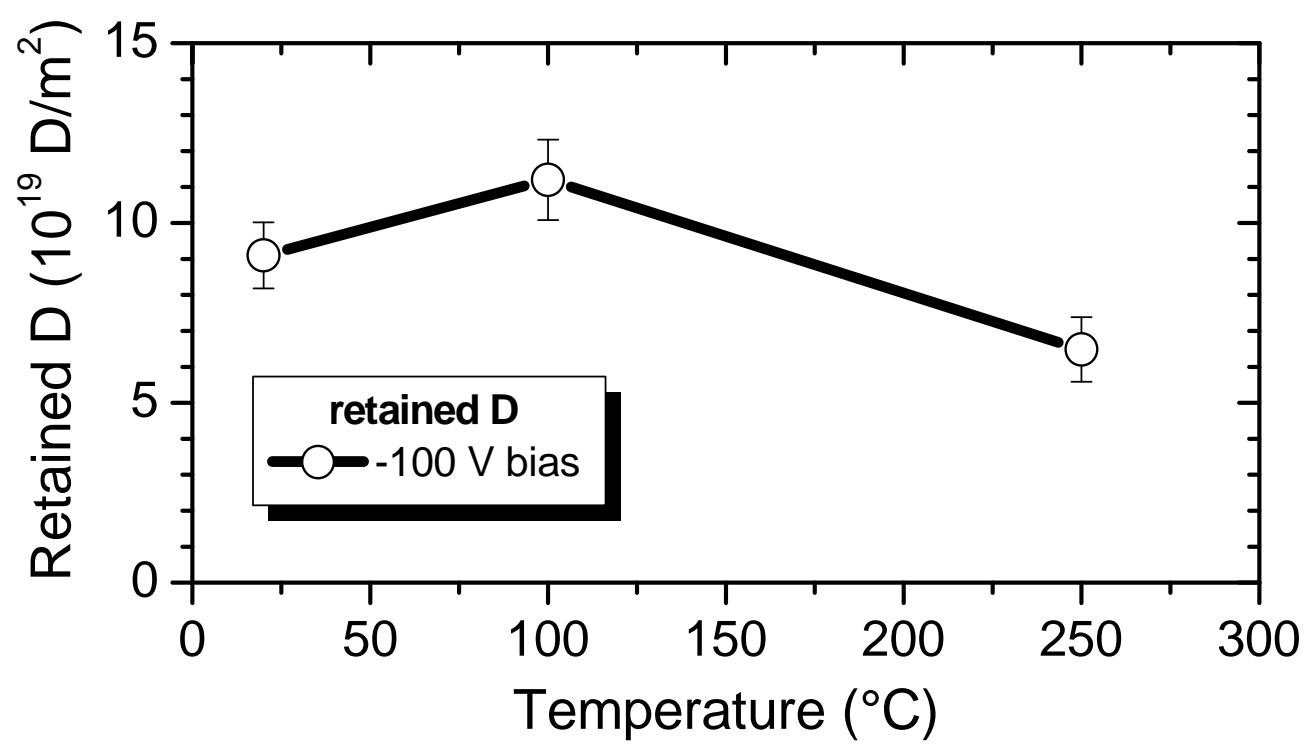


Fig. 6: Depth profiles of the composition of Be-oxide layers after implantation at different temperatures

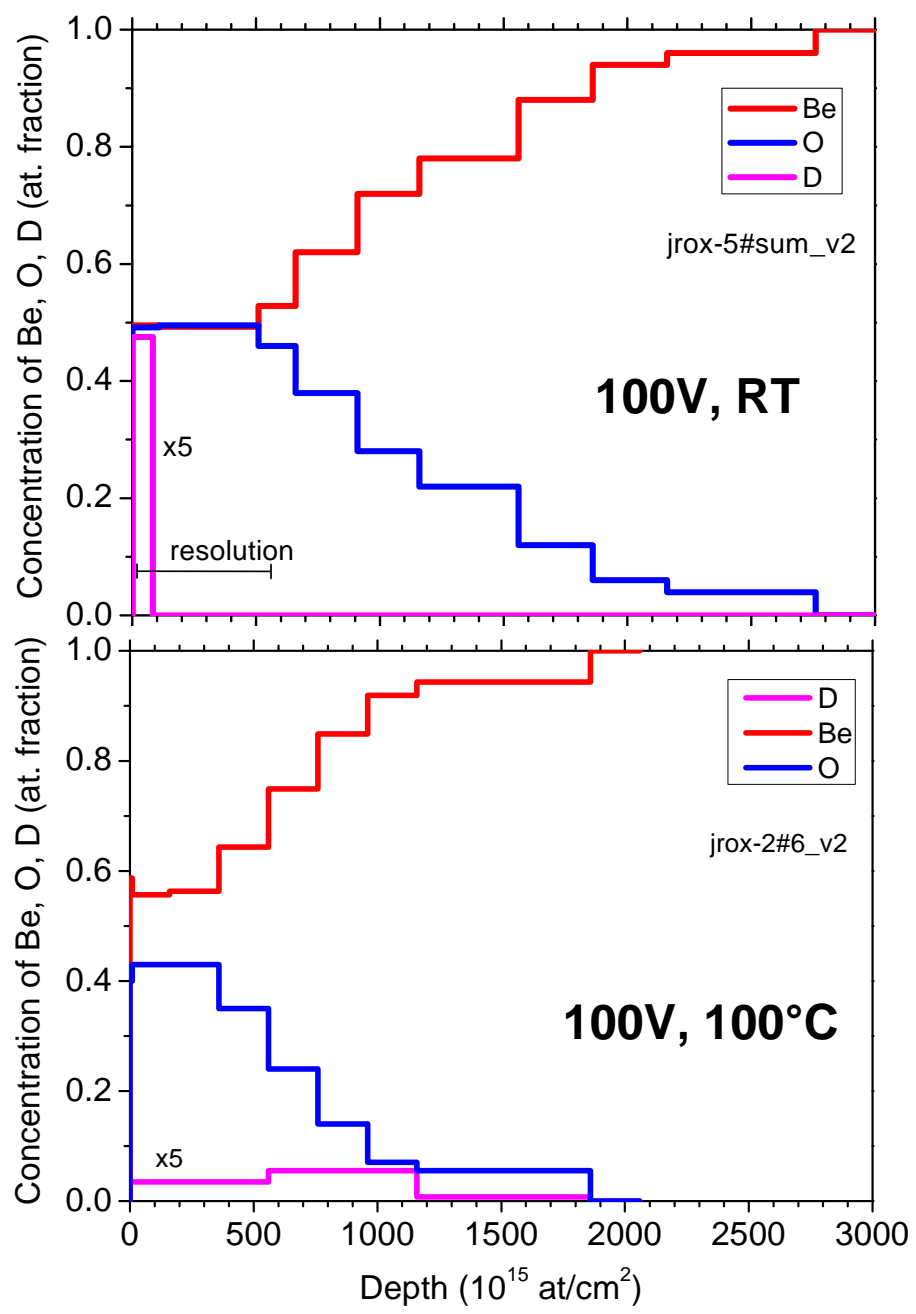




\section{References}

$\left.{ }^{1}{ }^{1}\right]$ A. Loarte, B. Lipschultz, A.S. Kukushkin, G.F. Matthews, P.C. Stangeby et al., "Chapter 4: Power and particle control”, Nucl. Fusion 47 (2007) S203

${ }^{2}$ ] Joachim Roth et al., J. Nucl. Mater. 390-391 (2009) 1

[3] R.A. Anderl, R.A. Causey, J.W. Davis, R.P. Doerner, G. Federici, A.A. Haasz, G.R.

Longhurst, W.R. Wampler, K.L. Wilson, J. Nucl. Mater. 273 (1999) 1

$\left[{ }^{4}\right]$ W. Möller, B.M.U. Scherzer and J. Bohdansky, "Retention and release of deuterium implanted into beryllium” IPP-JET Report No. 26; (March 1985)

[5] M. Reinelt, Ch. Linsmeier, J. Nucl. Mater. 390-391 (2009) 568

$\left[{ }^{6}\right]$ M. Oberkofler and Ch. Linsmeier, J. Nucl. Mater. 415 (2011) S724

[7] M. Mayer, J. Nucl. Mater. 240 (1997) 164

$\left[{ }^{8}\right]$ G. De Temmerman and R.P. Doerner, 2009 Nucl. Fusion 49042002

$\left[{ }^{9}\right]$ M. J. Baldwin, K. Schmid, R. P. Doerner, A. Wiltner, Ch. Linsmeier, J. Nucl. Mater. (2005) 337-339, 590-594

$\left[{ }^{10}\right]$ J. Roth, W.R. Wampler, W. Jacob, J. Nucl. Mater. 250 (1997) 23

${ }^{11}$ ] G. Ervin, Jr. and T. L. Mackay, J. Nucl. Mater. 12 (1964) 30

$\left.{ }^{12}\right]$ B.M.U. Scherzer, R.S. Blewer, R. Behrisch, R. Schulz, J. Roth, J. Borders, R. Langley, J. Nucl. Mater. 85-86 (1979) 1025

$\left[{ }^{13}\right]$ R. Behrisch, R.S. Blewer, J. Borders, R. Langley, J. Roth, B.M.U. Scherzer, R. Schulz, Radiation Effects 48 (1980) 221

$\left[{ }^{14}\right]$ M. Baldwin et al., “TMAP-7 simulation of D2 thermal release data from Be co-deposited layers” these PSI proceedings, P3-6

$\left.{ }^{15}\right]$ M. Mayer,"RESOLNRA: A new program for optimizing the achievable depth resolution of ion beam analysis methods", Nucl. Instr. and Meth. B 266 (2008) 1852

$\left[{ }^{16}\right]$ R. P. Doerner, M. J. Baldwin and K. Schmid, Phys. Scr. T111 (2004) 75

$\left[{ }^{17}\right]$ E. M. Hollmann and A. Yu. Pigarov: Phys. Plasma 9 (2002) 4330

$\left.{ }^{18}\right]$ J. F. Ziegler, ” SRIM - The Stopping and Range of Ions in Matter” http://www.srim.org $\left[{ }^{19}\right]$ W. Möller, W. Eckstein, J.P. Biersack, Comput. Phys.Commun. 51 (1988) 355

$\left[{ }^{20}\right]$ M. Oberkofler, R. Piechoczek and Ch. Linsmeier, Phys. Scr. T145 (2011) 014011

$\left[{ }^{21}\right]$ J. Roth, T. Schwarz-Selinger, V.Kh. Alimov, E.A. Markina, "Hydrogen isotope exchange in tungsten as removal method for tritium”, J. Nucl. Mater. Submitted for publication (2012) $\left.{ }^{22}\right]$ M. Mayer, SIMNRA User’s Guide, Tech. Rep. IPP 9/113, Garching, 1997, and www.rzg.mpg.de/ mam. 
$\left[{ }^{23}\right]$ J. Roth, B. Wampler, S. van Deusen, M. Oberkofler, ” D retention in and out-gassing from $\mathrm{BeO}$ on Be”, presentation at Hydrogen Workshop, Ringberg (2012), to be published $\left[{ }^{24}\right]$ J. Roth et al., J. Nucl. Mater. 85\&86 (1979) 1077

$\left.{ }^{25}\right]$ W. Eckstein, C. García-Rosales, J. Roth, W. Ottenberger, “Sputtering Data” Report IPP 9/82 (February 1993)

$\left[{ }^{26}\right]$ K. Sugiyama et al., Investigation of deuterium retention/release behaviour of berylliumrelated mixed materials towards tritium inventory control in ITER, this conference P3-056 